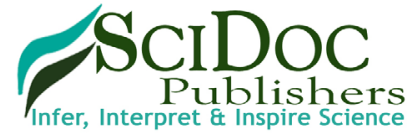

\section{Does Cinnamon Infusions Improve Blood Glucose Levels In Type 2 Diabetes Mellitus Subjects?}

T Sivapriya ${ }^{1 *}$, John $S^{2}$

${ }^{1}$ Assistant Professor, Department of Clinical Nutrition, SDNB Vaishnav College for Women, Chrompet, Chennai, TamilNadu, India.

${ }^{2}$ Associate Professor, Head, Department of Home Science, Womens Christian College, Chennai, India.

\title{
Abstract
}

Background: India is home to the second largest number of adults living with diabetes after China. Although modern diabetic drugs treat the condition effectively, prolonged usage leads to adverse effects. Plants have been a good source of medicine from ancient time. Among spices, the inner bark of cinnamon is authenticated as traditional medicine.

Objectives: To study whether cinnamon infusion improve blood glucose level in type 2 diabetes mellitus subjects.

Materials and Methods: In the current study, the effectiveness of seventy five $\mathrm{mL}$ of Cinnamomum zeylanicum infusion on plasma glucose, serum fructosamine and serum insulin of the selected subjects with type 2 diabetes were studied for a period of 45 days. Within-subjects design was used for the supplementation intervention.

Results: After 45 days supplementation, fasting glucose decreased ( $p<0.001)$ from 144.53 to $115.43 \mathrm{mg} / \mathrm{dL}$. Post prandial glucose decreased $(\mathrm{p}<0.001)$ from 205.66 to $164.33 \mathrm{mg} / \mathrm{dL}$. Serum fructosamine and insulin also showed marked improvements.

Conclusion: Supplementation with Cinnamomum Zeylanicum infusion for forty five days reduced fasting glucose, fructosamine and decreased insulin levels of subjects with elevated blood glucose.

Keywords: Cinnamon; Type 2 Diabetes; Plasma Glucose; Fructosamine; Insulin.

\section{Introduction}

Diabetes mellitus is a metabolic disorder characterized by the presence of hyperglycaemia due to defective insulin secretion, defective insulin action or both. The chronic hyperglycaemia of diabetes is associated with relatively specific long-term microvascular complications affecting the eyes, kidneys and nerves, as well as an increased risk for cardiovascular disease [1]. Diabetes is a result of rapid urbanization and life style changes in genetically predisposed individuals. Greatest numbers of diabetes patients are in the most economically productive age group in developing countries [2]. Although contemporary diabetic drugs treat the condition effectively, prolonged usage leads to adverse effects. Interest towards the use of complementary and alternative medicine in controlling diabetes is escalating among the consumers owing to the side effects of modern diabetic drugs. Apart from the adverse effect produced by modern medicine, people resort to complementary and alternative medicine due to their easy availability, low cost, minimum side effects, greater acceptance and their cultural beliefs. Thus, traditional medicines are gaining worldwide recognition at present [3]. Plants have been a good source of medicine from ancient time. (WHO. 2015)[4] has stated that about 90 percent of the people in developing countries use plants and its products as conventional medicine for their health care. Plantderived active principles representing bioactive compounds have ascertained their role for possible use in the treatment of diabetes $[5]$.

Metformin, which is a notable antidiabetic drug, was purified from the French lilac Galega officinalis L. The low cost of these compounds and the minimal side effects are other reasons behind the hunt for effective natural agents to be used as complementary and/or alternative medicine [6].

Among spices, the inner bark of cinnamon is most accepted, used universally for cooking and as medicines. The medicinal use of this plant has been authenticated in Ayurveda for over 6000 years [7].

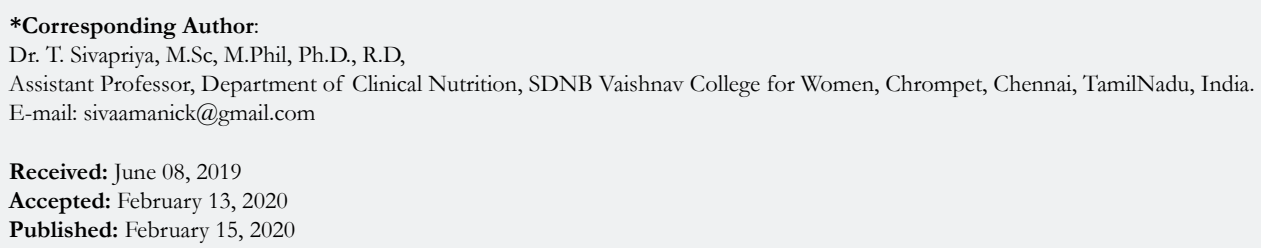

Copyright: T Sivapriya $^{\circ}$ 2020. This is an open-access article distributed under the terms of the Creative Commons Attribution License, which permits unrestricted use, distribution and reproduction in any medium, provided the original author and source are credited. 
Health benefiting property associated with the consumption of cinnamon could be attributed to its polyphenolic constituent. The main polyphenolic compound in cinnamon is a complex polymer proanthocyanidins [8].

Cinnamon polyphenols influence glucose metabolism within the cell through a variety of mechanisms which include increased autophosphorylation of the beta protein of the insulin receptor, decreased phosphatase activity, decreased glycogen synthase kinase- 3 beta activities and increased number of glutamine transport proteins [9]. Thus the objective of the present study has been framed to study the efficacy of cinnamon infusion in improving blood glucose levels of type 2 diabetes mellitus subjects.

\section{Materials and Method}

This study was approved by the Ethics Committee of the Independent Institutional Ethics Committee of Women's Christian College, Chennai (Ethical clearance No. WCC/HSC/11EC-2014:02) with amendments or comparable ethical standards.

The trial was intended to supplement study and compare the effect of $75 \mathrm{ml}$ aqueous extract of cinnamon infusion on blood glucose, serum insulin and serum fructosamine of the selected type 2 diabetes subjects, over a period of 45 days.

For the supplementation intervention, 'within-subjects design' was employed. Within-subjects design $[10,11]$ intends that the same subject is measured multiple times under different conditions. In this design, every subject acts as their own control, so that problems with matching age, gender and lifestyle, and the chances of confounding factors are reduced. According to within subject's design, subjects were assessed at three different periods of time, 15 days of base line study followed by 45 days of control phase and 45 days of supplementation period. Sixty subjects selected at random, received $75 \mathrm{ml}$ of infusion containing one gram of AECZ.

Before commencing the test procedure on the first study, a signed informed consent was obtained from each participant. The participants were informed by the investigator about the rationale of the trial and the subjects' cooperation needed during the supplementation. Additionally, the subjects were informed about the risks and benefits associated with the trial. The subjects were checked for eligibility in accordance with the specific inclusion and exclusion criteria, defined in the study protocol. All the subjects underwent a complete physical examination and the medical history of each participant was recorded.

Two kilograms of aqueous extract powder of Cinnamomum zeylanicum was procured from Navachetana Kendra, Health Care Limited, New Delhi with certificate of analysis. Packing of AECZ powder in tea bags was carried out in BGM Pharma, Madurai. Each tea bag contained one gram of AECZ powder. For the preparation of infusion, subjects were instructed to adhere to the method followed by [12]. About $100 \mathrm{ml}$ of water was boiled for 5 minutes from which $75 \mathrm{ml}$ of water was used for infusion preparation. The tea bag was gently dipped in a glass containing $75 \mathrm{ml}$ hot water and steeped for 15 minutes. A $75 \mathrm{ml}$ measuring cup was provided along with the teabags. All the subjects were allowed to take their routine diabetic diet, have regular physical activity and diabetic medicine. After the completion of formal procedures, on the $16^{\text {th }}$ day blood parameters were analysed on 8-hour fasting and post-prandial state for subjects. About $5 \mathrm{ml}$ of venous blood was drawn and analysed for fasting blood glucose level, serum fructosamine, fasting serum insulin, and post-prandial blood glucose.

On the first day $\left(60^{\text {th }}\right.$ day) of supplementation, $5 \mathrm{ml}$ of venous blood was drawn from the subjects for the analysis of blood parameters. The test group was supplied with thirty tea bags which contained $1 \mathrm{gm}$ of AECZ powder and requested to consume the infusion after breakfast each day for a period of thirty days. After one month, another 15 tea bags were distributed to them. General check-ups were carried out by a general physician every week to monitor pulse, blood pressure and any abnormalities. Subjects were also enquired about hypoglycaemic symptoms. Compliance to supplementation was monitored by using a compliance monitoring sheet as well as by telephone enquiries and SMS alerts.

Blood parameters were recorded on the $105^{\text {th }}$ day (end of the supplementation) to elicit the impact of supplementation. After the collection of blood samples the subjects discontinued the supplementation.

\section{Statistical Analysis}

The data was entered and then analysed using Microsoft Excel (2010) and SPSS Version 16. p value and t value were calculated.

\section{Results}

\section{Comparison of plasma sugar levels before and after supple- mentation}

The results of the plasma sugar for the subjects between the $60^{\text {th }}$ and 105 th day is presented in Table 2 . Table 2 indicates the mean fasting and postprandial plasma glucose, serum fructasamine and insulin levels before and after supplementation.

\section{Fasting and postprandial glucose levels}

It can be observed from Table 2 that there is a reduction in fasting and postprandial plasma glucose after the supplementation of cinnamon zeylanicum. For fasting plasma glucose, the values decreased from, from 144.53 to 115.43 . For post prandial glucose levels, there was a reduction from 205.66 to 164.33 after supplementation. The $\mathrm{p}$ values were significant at 5 percent level for both fasting and postprandial plasma glucose levels.

\section{Serum fructosamine levels}

The serum fructosamine testing determines the fraction of total glycated albumin proteins. Since the half-life of albumin is 18-21 days, the fructosamine levels can be used to measure the variation for short term supplementation like forty-five days.

From the table, it is evident that the levels of serum fructosamine dropped from 422.10 to 390.16 at the end of forty-five days' supplementation. The decrease was significant at $5 \%$ level and $\mathrm{p}$ value was 0.043 . 
Table 1. Test day schedule for the subjects.

\begin{tabular}{|c|c|}
\hline Days & Phase \\
\hline $0-15$ days & Baseline period (With medications) \\
\hline $16-60$ days & With medications, diet and physical activity \\
\hline $61-105$ days & With supplementation, medications, diet and physical activity \\
\hline
\end{tabular}

Table 2. Comparison of variation in plasma glucose levels before and after supplementation.

\begin{tabular}{|c|c|c|c|c|c|}
\hline \multirow[t]{2}{*}{ Blood Values } & \multirow{2}{*}{$\begin{array}{c}60^{\text {th }} \text { day } \\
\text { Mean } \pm \text { SD }\end{array}$} & \multirow{2}{*}{$\begin{array}{c}105^{\text {th }} \text { day } \\
\text { Mean } \pm \text { SD }\end{array}$} & \multirow{2}{*}{$\frac{\% \text { increment or reduction }}{\text { Day } 60 \text { vs. Day } 105}$} & \multicolumn{2}{|c|}{ Test of Significance } \\
\hline & & & & t-value & p-value \\
\hline Fasting plasma glucose $\mathrm{mg} / \mathrm{dl}$ & $144.53 \pm 25.86$ & $115.43 \pm 23.39$ & $\downarrow 20.6 \%$ & -12.403 & $<0.001 *$ \\
\hline Post-prandial Glucose $\mathrm{mg} / \mathrm{dl}$ & $205.66 \pm 31.43$ & $164.33 \pm 24.49$ & $\downarrow 20.3 \%$ & -9.076 & $<0.001 *$ \\
\hline Fructasamine $\mathrm{Mmol} / \mathrm{ml}$ & $422.16 \pm 79.63$ & $390.10 \pm 103.19$ & $\downarrow 7.6 \%$ & -1.752 & $<0.001 *$ \\
\hline Insulin $\mathrm{IU} / \mathrm{ml}$ & $6.33 \pm 9.54$ & $5.48 \pm 2.84$ & $\downarrow 12.7 \%$ & -0.503 & $0.619 \mathrm{NS}$ \\
\hline
\end{tabular}

* Significant at 5\% NS Not Significant

\section{Serum insulin levels}

As observed from the table, the fasting insulin levels decreased in response to cinnamon zeylanicum supplementation there was a decrease from 6.33 to 5.48 . Decrease in serum insulin levels was insignificant. Results suggest that consumption of cinnamomum zeylanicum infusion for a period of 45 days does not have any impact on the serum insulin levels.

\section{Discussion}

Cinnamon zeylanicum has shown to increase glucose uptake and glycogen synthesis. In addition, cinnamon zeylanicum aids in triggering the insulin receptor cascade system. As insulin plays a key role in lipid metabolism, the consumption of cinnamon zeylanicum would lead to improved glucose and blood lipids [13].

In a placebo-controlled, double-blind trial, supplementation with $500 \mathrm{mg}$ of water-extract of cinnamon for two months reduced fasting glucose, fructosamine, total cholesterol, and LDL cholesterol and enhanced insulin sensitivity of subjects with elevated blood glucose. Proanthocyanidins, in cinnamon, has a particularly high hydrophilic oxygen radical absorbance capacity/total phenolics ratio. Cinnamon bark extracts inhibited the formation of advanced glycation end products which results in diabetic complications [14].

Insulin resistance is a reduction in tissue response to insulin at one or more sites in the pathways of its action. Thus, diabetes causes greater alterations in the metabolic pathways regulated by insulin. Defects in glucose uptake, hexokinase activity and glycogen synthesis have been reported in insulin resistance. Methyl hydroxy chalcone polymer derived from cinnamon enhances the glucose uptake, glycogen synthesis and phosphorylation of insulin receptors suggesting that cinnamon could act as insulin mimetic [15].

When zeylanicum extracts were administered at the rate of $5 \mathrm{mg} /$ $\mathrm{kg}$ body weight in Wister rats, the plasma insulin was significantly increased. When zeylanicum extract was evaluated for its in vitro insulin releasing activity, stimulatory effect was observed, even at the lowest concentration. Cinnamon possesses direct insulin stimulatory effect [16].

\section{Conclusion}

Contemporary drugs prescribed for diabetes have a number of limitations, such as adverse effects, high rates of secondary failure and cost effectiveness. Recent studies demonstrate that plants are important for the prevention and control of diabetes. Cinnamon has similar efficacy without the side effects associated with conventional drug treatment and help in controlling blood glucose level, serum insulin level and fructosamine level.

\section{References}

[1]. Diabetes Canada Clinical Practice Guidelines Expert Committee, Punthakee Z, Goldenberg R, Katz P. Definition, Classification and Diagnosis of Diabetes, Prediabetes and Metabolic Syndrome. Can J Diabetes. 2018 Apr;42 Suppl 1:S10-S15. Pubmed PMID: 29650080.

[2]. Mohan V, Ruchi V, Gayathri R, Bai MR, Sudha V, Anjana RM, et al. Slowing the diabetes epidemic in the World Health Organization South-East Asia Region: the role of diet and physical activity. WHO South East Asia J Public Health. 2016 Apr;5(1):5-16. Pubmed PMID: 28604391

[3]. Wahlqvist ML. Can functional foods make a difference to disease prevention and control?. In Globalization, Diets and Noncommunicable Diseases. 2002: 1-21.

[4]. WHO . Fact sheet, Definition of Diabetes; 2015.

[5]. Rizvi SI, Mishra N. Traditional Indian Medicines Used for the Management of Diabetes Mellitus. J Diabetes Res. 2013;2013:712092. Pubmed PMID: 23841105.

[6]. El-Abhar HS, Schaalan MF. Phytotherapy in diabetes: Review on potential mechanistic perspectives. World J Diabetes. 2014 Apr 15;5(2):176-97. Pubmed PMID: 24748931.

[7]. Sangal A. Role of cinnamon as beneficial antidiabetic food adjunct: a review. Advances in Applied Science Research. 2011;2(4):440-50.

[8]. Martin KW, Ernst E. Herbal medicines for treatment of bacterial infections: a review of controlled clinical trials. J Antimicrob Chemother. 2003 Feb;51(2):241-6. Pubmed PMID: 12562687.

[9]. Wang JG, Anderson RA, Graham GM, Chu MC. et al., The effect of cinnamon extract on insulin resistance parameters in polycystic ovary syndrome: a pilot study. Fertil Steril. 2007;88(1):240-243. Pubmed PMID: 12562687.

[10]. Howitt D, Cramer D. Pearson Education Limited. $3^{\text {rd }}$ edn. Prentice hall, Harlow, United Kingdom; 2011.

[11]. Magistrelli A, Chezem JC. Effect of ground cinnamon on postprandial blood glucose concentration in normal weight and obese adults. J Acad Nutr Diet. 2012 Nov;112(11):1806-9. Pubmed PMID: 23102179.

[12]. Attieh HA, Abu Lafi S, Jaber S, Abu-Remeleh Q, Lutgen P, Akkawi M. Cin- 
namon bark water-infusion as an in-vitro inhibitor of $\beta$-hematin formation. J Med Plant Res. .2015;9(38):998-1005.

[13]. Khan A, Safdar M, Ali Khan MM, Khattak KN, Anderson RA. Cinnamon improves glucose and lipids of people with type 2 diabetes. Diabetes care. 2003 Dec;26(12):3215-8. Pubmed PMID: 1463380.

[14]. Anderson RA, Zhan Z, Luo R, Guo X, Guo Q, Zhou J, et al.Cinnamon extract lowers glucose, insulin and cholesterol in people with elevated serum glucose. J Tradit Complement Med. 2015 Apr 18;6(4):332-336. Pubmed PMID: 27774415.
[15]. Kannappan S, Jayaraman T, Rajasekar P, Ravichandran MK, Anuradha CV. Cinnamon bark extract improves glucose metabolism and lipid profile in the fructose-fed rat. Singapore Med J. 2006 Oct;47(10):858-63. Pubmed PMID:16990960.

[16]. Verspohl J, Bauer K, Neddermann E. Antidiabetic effect of cinnamon cassia and zeylanicum In Vivo and In Vitro. Phytother Res. 2005 Mar;19(3):203-6. Pubmed PMID: 15934022. 